EUROPEAN ORGANIZATION FOR NUCLEAR RESEARCH

European Laboratory for Particle Physics

Large Hadron Collider Project

LHC Project Report 508

\title{
AN EXPERIMENTAL STUDY OF COLD HELIUM DISPERSION IN AIR
}

\author{
M. Chorowski ${ }^{1}$, G. Konopka ${ }^{1}$ and G. Riddone ${ }^{2}$
}

\begin{abstract}
The Large Hadron Collider (LHC) presently under construction at CERN, will contain about 100 tons of helium mostly located in the underground tunnel and in caverns. Potential failure modes of the accelerator, which may be followed by helium discharge to the tunnel, have been identified and the corresponding helium flows calculated. To verify the analytical calculations of helium dispersion in the tunnel, a dedicated test set-up has been built. It represents a section of the LHC tunnel at a scale 1:13 and is equipped with a controllable helium relief system enabling the simulation of different scenarios of the LHC cryogenic system failures. Corresponding patterns of cold helium dispersion in air have been observed and analysed with respect to oxygen deficiency hazard. We report on the test set-up and the measurement results, which have been scaled to real LHC conditions.
\end{abstract}

1 Wroclaw University of Technology, Wroclaw, Poland 2 CERN, LHC Division

Presented at the 2001 Cryogenic Engineering Conference and International Cryogenic Materials Conference CEC/ICMC 2001

16-20 July 2001, Madison, Wisconsin, USA

\footnotetext{
Administrative Secretariat

LHC Division

CERN

CH - 1211 Geneva 23

Switzerland

Geneva, 19 October 2001
} 


\title{
AN EXPERIMENTAL STUDY OF COLD HELIUM DISPERSION IN AIR
}

\author{
M. Chorowski ${ }^{1}$, G. Konopka ${ }^{1}$, G. Riddone ${ }^{2}$ \\ ${ }^{1}$ Wroclaw University of Technology \\ 50-370 Wroclaw, Poland \\ ${ }^{2}$ CERN, LHC Division \\ 1211 Geneva, Switzerland
}

\begin{abstract}
ABTRACT
The Large Hadron Collider (LHC) presently under construction at CERN, will contain about 100 tons of helium mostly located in the underground tunnel and in caverns. Potential failure modes of the accelerator, which may be followed by helium discharge to the tunnel, have been identified and the corresponding helium flows calculated. To verify the analytical calculations of helium dispersion in the tunnel, a dedicated test set-up has been built. It represents a section of the LHC tunnel at a scale 1:13 and is equipped with a controllable helium relief system enabling the simulation of different scenarios of the LHC cryogenic system failures. Corresponding patterns of cold helium dispersion in air have been observed and analysed with respect to oxygen deficiency hazard. We report on the test set-up and the measurement results, which have been scaled to real LHC conditions.
\end{abstract}

\section{INTRODUCTION}

As a result of the Preliminary Risk Analysis performed at CERN [1] the worst failures of the LHC cryogenic system that might be followed by helium discharge to the machine tunnel, have been identified. The potential amount of helium vented into the machine tunnel, caverns, shafts and surface buildings has also been estimated [2]. In case of helium discharge to the tunnel, the vented helium will be mixed with the ventilation air and the oxygen concentration of the mixture could drop below $18 \%$ in case of perfect mixing. However, in case of imperfect mixing and helium-air stratification, the oxygendeficiency hazard at floor level is expected to be reduced. The aim of the study was to observe different helium-air mixture flow patterns in a dedicated test tunnel and to investigate under which conditions stratification, which reduces Oxygen Deficiency Hazard (ODH) at floor level, can occur. The work also contributed for better understanding of basic physics of the mixing and flowing of gases characterized by significant different temperatures and densities. 


\section{DESCRIPTION OF THE TEST SET-UP}

The test set-up is shown in Figures 1 and 2. The LHC tunnel is scaled down by a factor of 13 and the resulting inner diameter of the test pipe (3) is $0.292 \mathrm{~m}$. Helium is supplied by a dewar vessel (1) and vented to the pipe (3) made of stainless steel (3a - air inflow zone) and transparent Plexiglas modules ( $3 \mathrm{~b}-$ measurement zone). It is possible to interchange the sequence of the pipe modules to observe the flow pattern at different locations. The inlet helium mass-flow can be controlled by changing the nozzle and by acting on the flow control valve installed in the transfer line. A heater installed in the continuous flow cryostat and connected with the temperature controller allows controlling the initial temperature of helium.

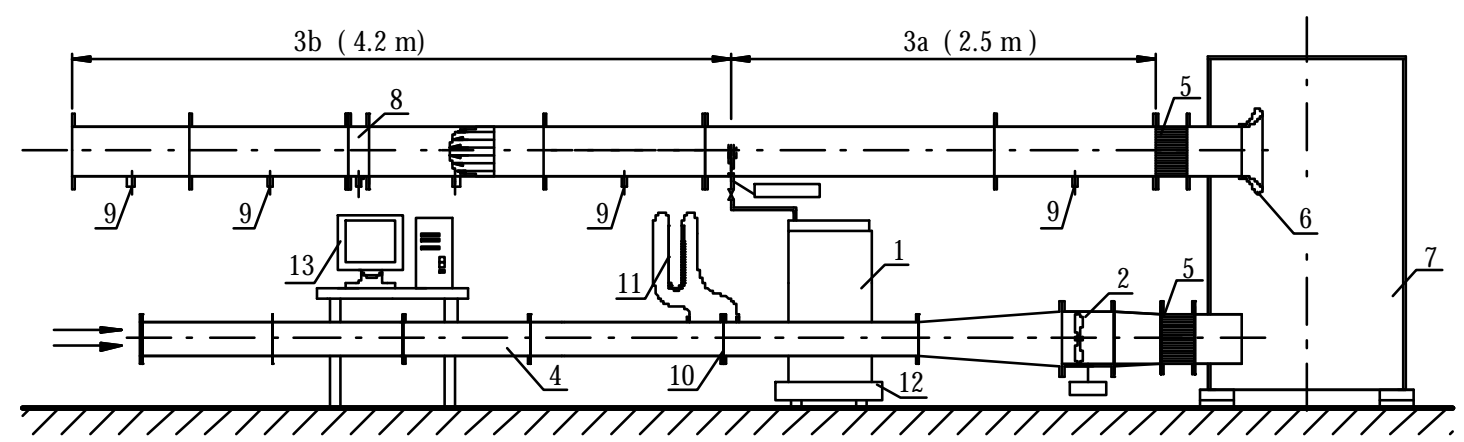

FIGURE 1. Scheme of the test set-up: 1 - helium supply system (LHe dewar, transfer line, continuous flow cryostat with exchangeable nozzles, temperature controller), 2 - axial-flow fan with a speed regulator, 3 - pipe of diameter 300/292 mm, (3a - inflow zone, 3b - measurement zone), 4 - inlet pipe of diameter $200 \mathrm{~mm}, 5$ - flow straightener, 6 -converging cone, 7 - air reservoir of $1200 \mathrm{~mm}$ diameter, 8 - sensor set (thermocouples, oxygen concentration sensors), 9 - hot wire anemometer probe entry, 10 - orifice plate, 11 - pressure gauge, 12 - electronic balance, 13 - data acquisition set.

The observed air velocity profiles resulted to be turbulent as shown in Figure 3. The cold helium is supplied by a dewar pressurised by warm helium tapped from gas cylinders. A set of sensors (5) fitted in a smaller module which can be moved along the measurement zone ( $3 b)$ is used to determine the helium-air mixture properties. The sensors allow to measure the following parameters: helium mass flow, helium temperature at the inlet and mixture temperature along the test tunnel, air and mixture velocity, oxygen concentration at the distance of up to $2.5 \mathrm{~m}$ from the vent.

The oxygen deficiency meters are based on the limiting current method using zirconia solid electrolyte. Prior to measurements these sensors have been calibrated as shown in Figure 4. For oxygen concentrations higher than 3\%, the error with respect to the theoretical curve is about $2.5 \%$. This means that for a real $\mathrm{O}_{2}$ concentration of $12 \%$, the sensor output would be $14.5 \%$. The differences between actual and indicated oxygen concentrations can be caused by interactions of light helium molecules with a diffusion barrier.

An alternative method of helium concentration measurements based on acoustic topography has been considered. Sound velocity in helium differs significantly from that in air, thus basing on sound velocity distribution it is feasible to reconstruct the helium distribution. The test set-up will be equipped with 12 transceivers working on $100 \mathrm{kHz}$ frequency. 


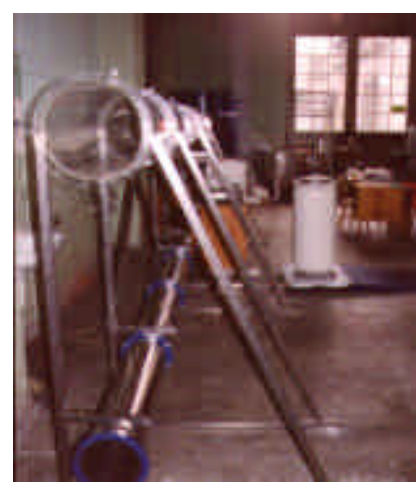

FIGURE 2. General view of the test set-up

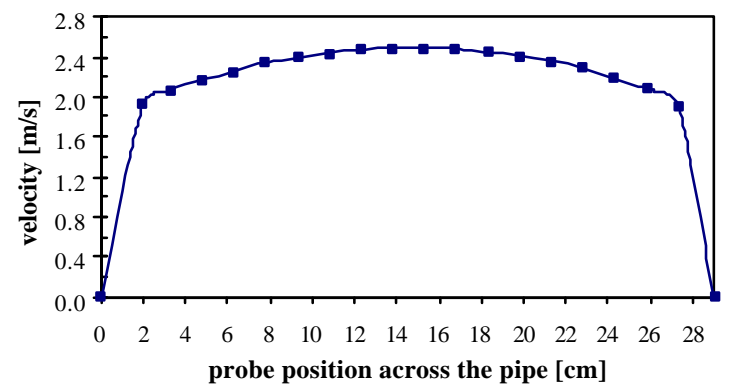

FIGURE 3. Typical air velocity profile observed in the test set-up

\section{FLOW ANALYSIS OF HELIUM-AIR MIXTURE}

\section{Turbulent jet and onset of buoyancy force effect}

When a turbulent jet of helium is vented into a test tunnel, intensive helium mixing with air is observed. Velocity and helium concentration along the jet axis can be calculated from the model based on the momentum conservation along the jet axis and on the assumption that the cone angle of a cryogenic jet can be considered as constant [3]. Due to the helium mixing with air, the jet density changes along its axis and the region of positive buoyancy is reached at a certain distance from the jet outlet (see Figure 5). The minimum density of the air-helium mixture, as well as the oxygen content in the mixture, depend on the initial helium temperature, as shown in Figures 6 and 7. For initial helium temperatures higher that $55 \mathrm{~K}$, the buoyancy is positive already at the jet outlet and the minimum density is reached as soon as the air is mixed with the helium. As a consequence the potential stratified low-density layer will be composed of helium-air mixture with non-zero oxygen content.

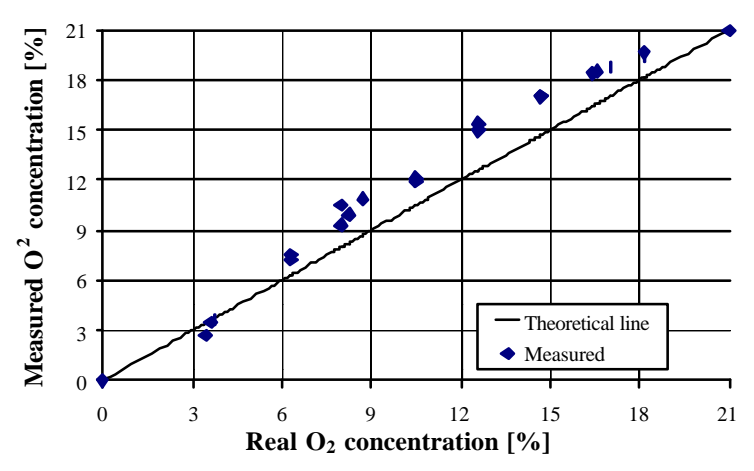

FIGURE 4. Calibration of oxygen deficiency meters

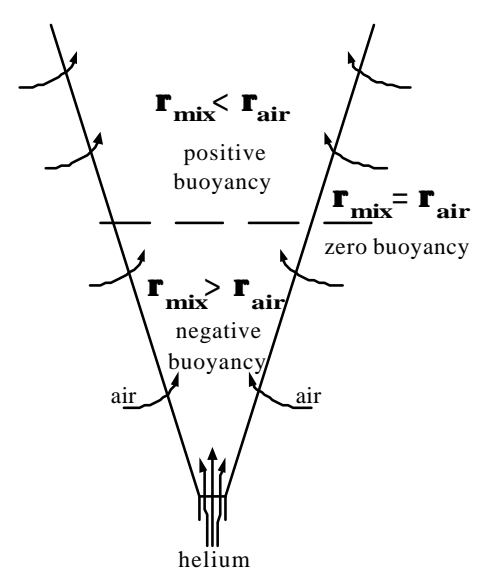

FIGURE 5. Helium-air jet divided in buoyancy zones 


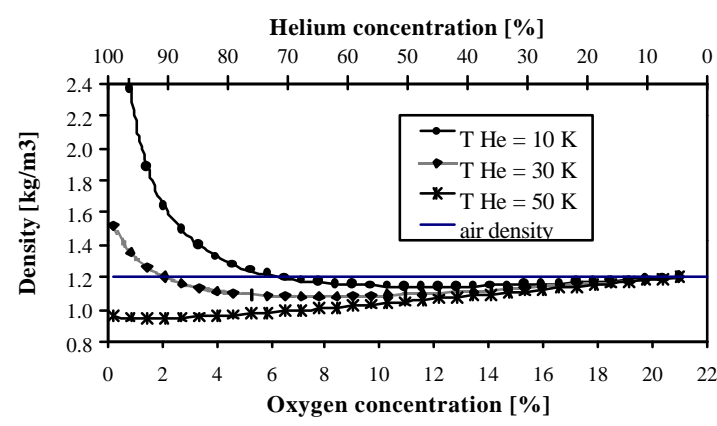

FIGURE 6. Density of mixture versus oxygen concentration

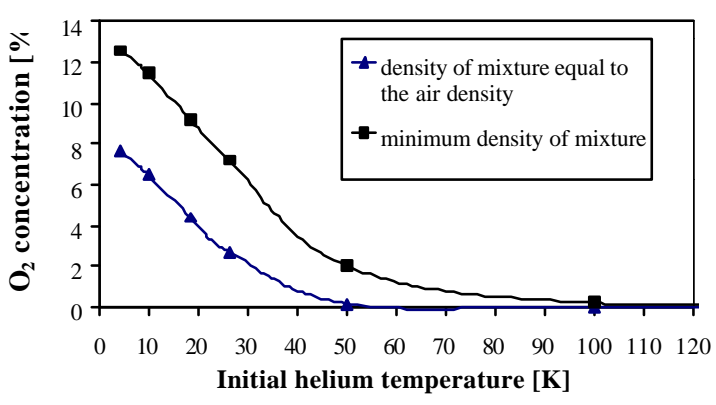

FIGURE 7. Oxygen concentration in helium-air mixture versus initial helium temperature

\section{Onset of helium rich layer stratified flow}

The onset of helium rich layer stratified shear flow is observed when the buoyancy forces are dominant over the inertia forces. For helium vented into the tunnel, this condition [see eq. (1)] can be expressed by using the stratification or Bakke number (L) [4] as follows:

$$
\mathrm{L}=\frac{w}{\sqrt[3]{\frac{g \cdot q_{v} \cdot \Delta \rho}{d \cdot \rho}}} \quad \text { where } \quad \mathrm{L}^{3}=\frac{\mathrm{Re}^{2}}{\mathrm{Ar}}
$$

where Re and Ar are the Reynolds and Archimedes numbers respectively, $w[\mathrm{~m} / \mathrm{s}]$ the air velocity, $g\left[\mathrm{~m} / \mathrm{s}^{2}\right]$ the gravitational acceleration, $\Delta \rho\left[\mathrm{kg} / \mathrm{m}^{3}\right]$ the density gradient between the two fluids, $\rho\left[\mathrm{kg} / \mathrm{m}^{3}\right]$ the density of the flowing air, $q_{v}\left[\mathrm{~m}^{3} / \mathrm{s}\right]$ the volume flow rate of helium and $d[\mathrm{~m}]$ the tunnel diameter.

If $\mathrm{L}<2$, stratification may occur. The critical value $\mathrm{L}_{\mathrm{cr}}=2$ of the stratification number has been determined experimentally, however a full mixing has been observed only for $\mathrm{L}_{\mathrm{cr}}>5$ [4]. The corresponding critical velocity of air is given by eq. (2):

$$
w_{c r}=\mathrm{L}_{c r} \cdot \sqrt[3]{\frac{g \cdot q_{v} \cdot \Delta \rho}{d \cdot \rho}}
$$

\section{Stability of a stratified shear flow}

A stability criterion for a stratified shear flow can be expressed by using the Richardson number Ri as given below.

$$
\mathrm{Ri}=\frac{g}{\rho} \cdot \frac{\frac{d \rho}{d z}}{\left(\frac{d w}{d z}\right)^{2}}
$$

If $\mathrm{Ri}>1$, the stratified shear flow is stable. The Richardson number results from thermodynamic considerations, such as comparison of variation of potential and kinetic energies in a mixing process. 


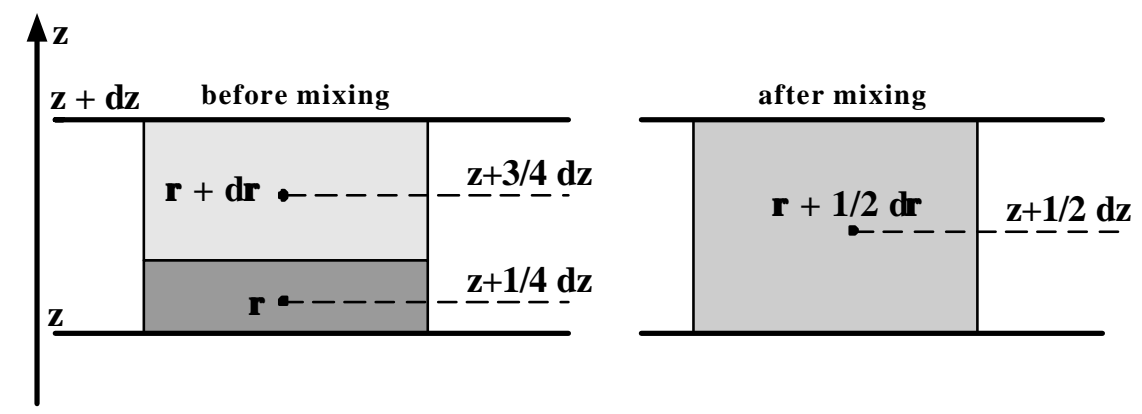

FIGURE 8. Unit volume elements of stratified fluids

We consider two adjacent unit volumes of slightly different densities and velocities before the mixing, as shown in Figure 8. As a result of the mixing the density and velocity become uniform.

The initial and final potential energies $E_{p 1}$ and $E_{p 2}$ are equal to:

$$
E_{p 1}=g \rho\left(z+\frac{d z}{4}\right)+g(\rho+d \rho) \cdot\left(z+\frac{3 \cdot d z}{4}\right) \quad E_{p 2}=2 g\left(\rho+\frac{d \rho}{2}\right) \cdot\left(z+\frac{d z}{2}\right)
$$

The change in potential energy is:

$$
d E_{p}=-\frac{1}{4} \cdot g \cdot d \rho \cdot d z
$$

The initial and final kinetic energies $E_{k 1}$ and $E_{k 2}$ are (the velocity of the mixed fluid element results from the momentum conservation):

$$
E_{k 1}=\frac{1}{2} \cdot \rho \cdot w^{2}+\frac{1}{2} \cdot \rho \cdot(w+d w)^{2} \quad E_{k 2}=\frac{1}{2} \cdot \frac{2 \rho \cdot(2 w+d w)^{2}}{4}
$$

The change in kinetic energy is:

$$
d E_{K}=-\frac{1}{4} \cdot \rho \cdot(d w)^{2}
$$
eq. (3).

The stability of a stratified shear flow occurs when $d E_{K}<d E_{p}$ which leads to the

\section{EXPERIMENTAL RESULTS}

\section{Cold helium vented into air}

Table 1 gives the input and output parameters observed for cold helium vented into the test tunnel, where $q_{m} \mathrm{He}$ is the measured helium mass flow rate, $w_{A i r}$ the measured air velocity, $\mathrm{Re}_{\text {Air }}$ the Reynolds number calculated for air, $w_{\text {mix }}$ the measured helium-air mixture velocity, $T_{m i x}$ the temperature of the mixture measured at the tunnel outlet, $\rho_{\text {mix }}$ the mixture density calculated for $T_{m i x}$ and oxygen concentration resulting from Figure 7 for minimum density condition, $\mathrm{L}$ the stratification number calculated for $q_{m}, w_{\text {Air }}$ and $\rho_{\text {mix min }}$, $\mathrm{Ri}$ the Richardson number calculated for $\rho_{\text {mix }}, \rho_{\text {air }}, w_{\text {mix }}\left(w_{\text {air }}=0\right), w_{\text {air }}$ cr the critical air 
velocity for $\mathrm{L}=5$; $\mathrm{Re}_{\mathrm{cr}}$ the Reynold number calculated for $w_{\text {air }}$ r and $\mathrm{O}_{2}$ the average oxygen concentrations measured in different layers as shown in Figure 9. For the events No 1, 2 and 3 of Table 1, Figure 9 gives also the average value of oxygen concentration for each distinguished layer. The dots represent the locations of the oxygen concentration sensor around the tunnel at a distance of $2.4 \mathrm{~m}$ from the vent.

For these tests the initial helium temperature was kept at $25 \mathrm{~K}$. For this temperature a minimum density of $1.1 \mathrm{~kg} / \mathrm{m}^{3}$ is obtained when the oxygen content is of $8.8 \%$. Three different flow patterns can be distinguished with respect to the helium mass flow and air velocity (see Figure 9):

- Case a: fully stratified flow with a mist visible only in the upper part of the tunnel and no change in oxygen concentration in the lower part. The stratification number $L$ is equal to 0 (helium vented into stagnant air) and $\mathrm{Ri}$ is higher than 1 . The mixture velocity $w_{\text {mix }}$ is an average velocity of the upper layers schematically shown in Figure 8 and measured at a distance of $2.4 \mathrm{~m}$ from the vent. The air in the lower layer of the tunnel remains static (see Figures $10 \mathrm{a}$ and $10 \mathrm{~b}$ ).

- Case b: partly stratified flow with oxygen concentration drop noticeable in the lower part of the tunnel. The stratification number varies between 2 and 5. The mixture velocity $w_{\text {mix }}$ refers to the average velocity measured in the tunnel. No velocity difference between the layers is observed (see Figure 10c).

- Case c: homogenous flow with no oxygen concentration gradient across the tunnel. The stratification number $\mathrm{L}$ is higher than 5 . The mixture velocity $w_{\text {mix }}$ corresponds to the average velocity measured in the tunnel (see Figure 10d).

The minimum measured oxygen concentrations correspond to the values resulting from Figure 7.
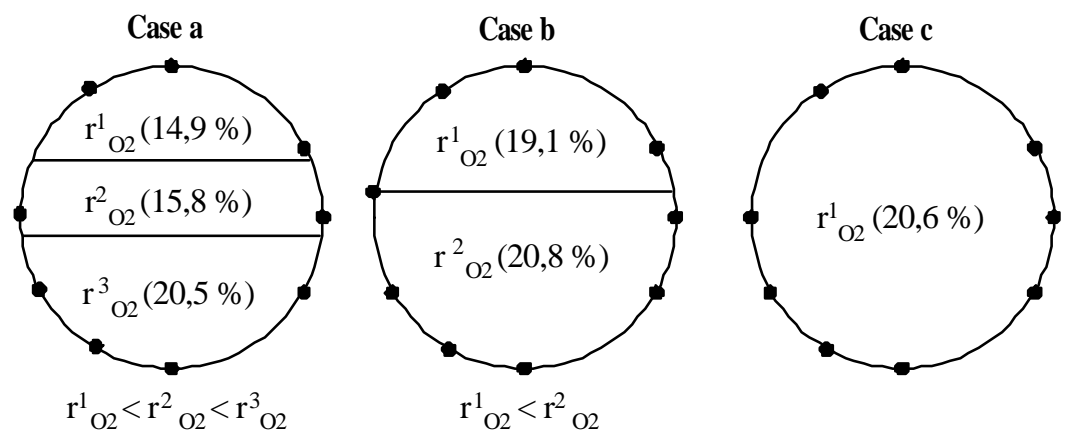

FIGURE 9. Schematic representation of the observed flow patterns showing oxygen concentration stratification

TABLE 1. Input and output parameters for cold helium vented into the test tunnel

\begin{tabular}{cccccccccccl}
\hline No. & $\begin{array}{c}q_{m H e} \\
{[\mathrm{~g} / \mathrm{s}]}\end{array}$ & $\begin{array}{c}w_{\text {Air }} \\
{[\mathrm{m} / \mathrm{s}]}\end{array}$ & $\begin{array}{c}\mathrm{Re}_{\text {Air }} \\
{[=]}\end{array}$ & $\begin{array}{c}w_{\text {mix }} \\
{[\mathrm{m} / \mathrm{s}]}\end{array}$ & $\begin{array}{c}T_{\text {mix }}[\mathrm{K}] \\
{[\mathrm{Ng} / \mathrm{m}]}\end{array}$ & $\begin{array}{c}\rho_{\text {mix }} \\
{[=]}\end{array}$ & $\begin{array}{c}\mathrm{Ri} \\
{[=]}\end{array}$ & $\begin{array}{c}w_{\text {Aircr }} \\
{[\mathrm{m} / \mathrm{s}]}\end{array}$ & $\begin{array}{c}\mathrm{Re}_{\mathrm{cr}} \\
{[=]}\end{array}$ & $\begin{array}{c}\mathrm{O}_{2} \\
{[\%]}\end{array}$ \\
\hline 1 & 0.25 & 0 & 0 & 0.31 & 280 & 0.343 & 0.0 & 38.2 & 0.43 & 87318 & a) $14.9 / 15.8 / 20.5$ \\
2 & 0.25 & 0.23 & 47012 & 0.44 & 281 & 0.342 & 2.6 & - & 0.43 & 87562 & b) $19.1 / 20.8$ \\
3 & 0.25 & 0.52 & 106288 & 0.70 & 285 & 0.337 & 6.1 & - & 0.43 & 87562 & c) 20.6 \\
4 & 0.60 & 0 & 0 & 0.60 & 275 & 0.349 & 0.0 & 4.4 & 0.57 & 117234 & a) $14.5 / 15.6 / 20.5$ \\
5 & 1.10 & 0.52 & 106288 & 1.40 & 280 & 0.343 & 3.7 & - & 0.70 & 143483 & b) $16.3 / 20.5$ \\
6 & 1.10 & 0.63 & 128772 & 1.50 & 283 & 0.339 & 4.5 & - & 0.70 & 143483 & b) $16.5 / 20.5$ \\
7 & 1.10 & 1.74 & 355656 & 2.60 & 287 & 0.335 & 12.4 & - & 0.70 & 143483 & c) 20.8 \\
8 & 1.85 & 0 & 0 & 1.20 & 268 & 0.358 & 0.0 & 1.3 & 0.83 & 170632 & a) $4.1 / 5.4 / 20.0$ \\
9 & 1.85 & 0.63 & 128772 & 1.50 & 271 & 0.354 & 3.7 & - & 0.83 & 170632 & b) $14.3 / 20.0$ \\
10 & 1.85 & 1.25 & 255500 & 2.10 & 280 & 0.343 & 7.4 & - & 0.83 & 170632 & c) 20.8 \\
\hline
\end{tabular}

Figure 10 shows typical pictures of the observed flow patterns. Moisture is visible due to the mixing temperature being lower than the corresponding dew point temperature. 

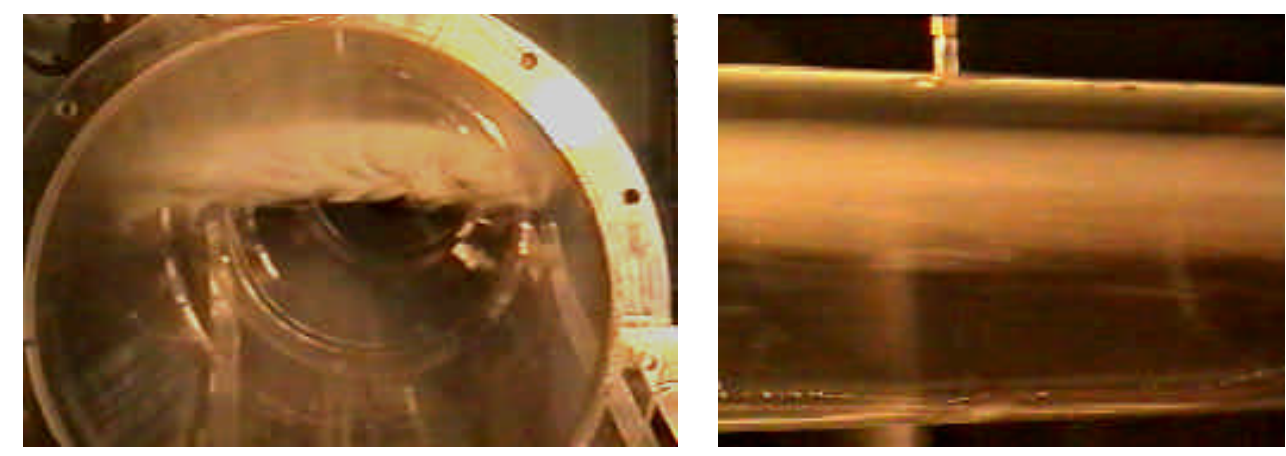

a)

b)
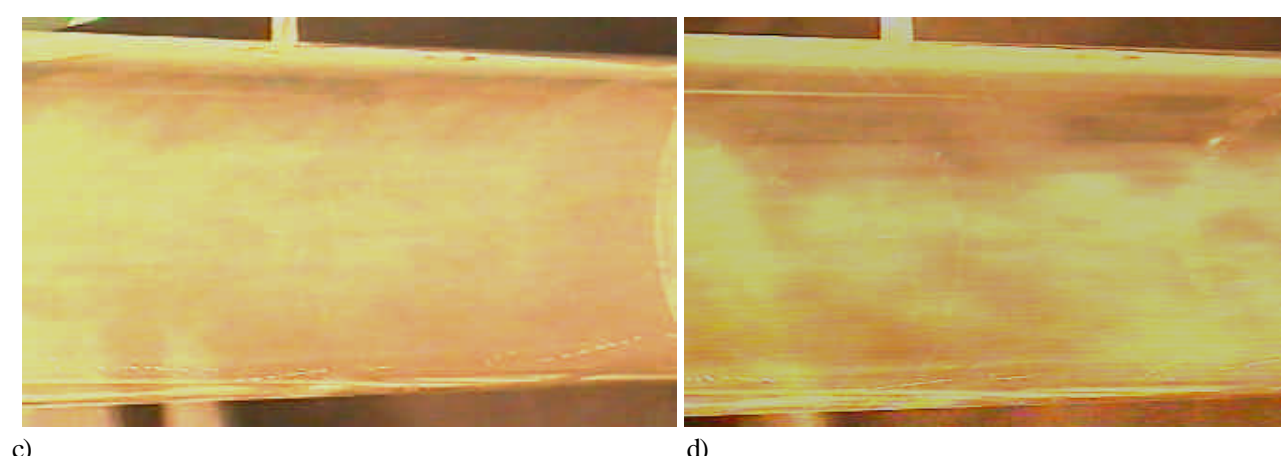

FIGURE 10. Pictures of helium-air mixture flow through the tunnel; a) front view - air velocity equal zero (Case a); b) side view - air velocity equal zero (Case a); c) side view - air velocity equal 1,4 m/s (Case b); d) side view - air velocity equal 1,74 m/s (Case c).

\section{Warm helium venting}

Warm helium has been vented from the compressed gas cylinder at the temperature of $290 \mathrm{~K}$ and at the absolute pressure of $0.13 \mathrm{MPa}$. The results are shown in Table 2. A stratified flow was observed for the stratification number $\mathrm{L}$ equal to 0 and 0.49 , however a full mixing occurred even for $\mathrm{L}$ as low as 1.68.

TABLE 2. Input and output parameters for warm helium vented into the test tunnel.

\begin{tabular}{ccccccccccc}
\hline No. & $q_{m H e}$ & $w_{\text {Air. }}$ & $\operatorname{Re}_{\text {Air }}$ & $w_{\text {mix }}$ & $T_{\text {mix. }}$ & $\mathrm{L}$ & $\mathrm{Ri}$ & $w_{\text {Aircr }}$ & $\mathrm{Re}_{\mathrm{cr}}$ & $\mathrm{O}_{2 .}$ \\
& {$[\mathrm{g} / \mathrm{s}]$} & {$[\mathrm{m} / \mathrm{s}]$} & {$[=]$} & {$[\mathrm{m} / \mathrm{s}]$} & {$[\mathrm{K}]$} & {$[=]$} & {$[=]$} & {$[=]$} & {$[=]$} & {$[\%]$} \\
\hline 1 & 1.1 & 0 & 0 & 0.20 & 290 & 0.00 & 55.70 & 2.88 & 589693 & $\mathrm{a}) 12.0 / 13.0 / 20.8$ \\
2 & 1.1 & 0.48 & 57713 & 0.61 & 290 & 0.49 & - & 2.88 & 589693 & b) $16.0 / 18.0$ \\
3 & 1.1 & 0.97 & 199934 & 1.21 & 290 & 1.68 & - & 2.88 & 589693 & c) 20.8 \\
\hline
\end{tabular}

\section{SCALING OF THE RESULTS TO LHC CONDITIONS}

Worst-case failure modes for the LHC cryogenic system are [2]:

- Failure 1: Break of supercritical helium header of the cryogenic distribution line (estimated peak flow of $3 \mathrm{~kg} / \mathrm{s}$ followed by $1 \mathrm{~kg} / \mathrm{s}$ helium flow at $19 \mathrm{~K}$ ),

- Failure 2: Break of the connection in between the cryogenic distribution line and the cryomagnets (estimated peak flow of $20 \mathrm{~kg} / \mathrm{s}$ due to the cold mass evacuation followed by $2 \mathrm{~kg} / \mathrm{s}$ helium flow at $10 \mathrm{~K}$ ),

- Failure 3: Break of the helium ring line (peak flow $14 \mathrm{~kg} / \mathrm{s}$ at $290 \mathrm{~K}$ ).

The ventilation concept for the LHC is based on an air velocity of $0.55 \mathrm{~m} / \mathrm{s}$ (nominal) and $0.88 \mathrm{~m} / \mathrm{s}$ (emergency). Calculations of stability criteria have been done for 
above helium mass flows and air velocities and the results are given in Table 3, where $q_{m} \mathrm{He}$ and $T_{H e}$ are calculated at the initial helium conditions, $\rho_{\text {mix min }}$ is the minimum mixture density for the corresponding $T_{H e}$; $T_{m i x}$ the mixture temperature at ceiling level, $\mathrm{O}_{2 \max }$ and $\mathrm{O}_{2 \text { min }}$ the oxygen concentration at the floor and the ceiling levels respectively and $\rho_{\text {mix }}$ the minimum density of mixture for $\mathrm{T}=290 \mathrm{~K}$. The values of stratification number L indicate, that a helium rich stratified layer is to be expected in the upper part of the tunnel. Due to a peak discharge of $475 \mathrm{~kg}$ of helium in case of failure 2, the tunnel will be fully filled with helium-air mixture at the distance of $84 \mathrm{~m} \mathrm{[2].}$

TABLE 3. Input and output parameters for the worst-case failure modes for the LHC cryogenic system

\begin{tabular}{cccccccccccc}
\hline $\begin{array}{c}q_{m H e} \\
{[\mathrm{~kg} / \mathrm{s}]}\end{array}$ & $\begin{array}{c}T_{H \mathrm{e}} \\
{[\mathrm{K}]}\end{array}$ & $\begin{array}{c}w_{\text {Air }} \\
{[\mathrm{m} / \mathrm{s}}\end{array}$ & $\begin{array}{c}\mathrm{Re}_{\text {Air }} \\
{[=]}\end{array}$ & $\begin{array}{c}\rho_{\text {mixmin }} \\
{\left[\mathrm{kg} / \mathrm{m}^{3}\right]}\end{array}$ & $\begin{array}{c}T_{\text {mix }} \\
{[\mathrm{K}]}\end{array}$ & $\begin{array}{c}\mathrm{O}_{2 \max } \\
{[\%]}\end{array}$ & $\begin{array}{c}\mathrm{O}_{2 \min } \\
{[\%]}\end{array}$ & $\begin{array}{c}\boldsymbol{\rho}_{\text {mix }} \\
(\mathrm{T}=290 \mathrm{~K})\end{array}$ & $\begin{array}{c}\mathrm{L} \\
{[=]}\end{array}$ & $\begin{array}{c}w_{\text {Aircr }} \\
{[\mathrm{m} / \mathrm{s}]}\end{array}$ & Failure \\
\hline 1 & 19 & 0.55 & 1376941 & 1.19 & 170 & 20.5 & 9.8 & 0.652 & 1.02 & 2.69 & 1 \\
2 & 10 & 0.55 & 1376941 & 1.14 & 186 & 20.5 & 11.0 & 0.735 & 0.9 & 3.05 & 2 \\
14 & 290 & 0.55 & 1376941 & 0.65 & 290 & 20.5 & 0 & 0.165 & 0.10 & 28.69 & 3 \\
1 & 19 & 0.88 & 2203106 & 1.19 & 170 & 20.5 & 9.8 & 0.652 & 1.64 & 2.69 & 1 \\
2 & 10 & 0.88 & 2203106 & 1.14 & 186 & 20.5 & 11.0 & 0.735 & 1.44 & 3.05 & 2 \\
14 & 290 & 0.88 & 2203106 & 0.65 & 290 & 20.5 & 0 & 0.165 & 0.15 & 28.69 & 3 \\
\hline
\end{tabular}

\section{CONCLUSIONS}

When helium is vented into a tunnel, stratification followed by a stratified shear flow occurs if the dimensionless criteria based on Bakke and Richardson numbers are fulfilled. In particular a stratified flow is observed for an air velocity equal to zero. Helium vented into the tunnel will mix with the air until the lowest density of the mixture is reached. The content of oxygen in a stratified layer depends on the initial helium temperature, which will be about $12 \%$ at $4.5 \mathrm{~K}$. For the conditions expected in the LHC tunnel following the worst case scenario failures for the cryogenic system, a helium-air stratification is expected to occur as the ventilation velocity is much lower than the critical value given by eq. (2) and the corresponding stratification number $\mathrm{L}$ is always lower than 2. As a consequence, the oxygen deficiency in the lower part of the tunnel is reduced as compared to the pessimistic case of perfect mixing.

\section{ACKNOWLEDGEMENTS}

This work was done in the framework of a collaboration agreement between CERN and Wroclaw University of Technology.

\section{REFERENCES.}

1. Chorowski M., Lebrun Ph., Riddone G., "Preliminary Risk Analysis of the LHC Cryogenic System," in Advances in Cryogenic Engineering 45B, edited by Quan-Sheng Shu et al., Plenum, New York, 2000, pp. 1309-1316.

2. Chorowski M., Konopka G., Riddone G., "Helium discharge and dispersion in the LHC acceleration tunnel following failure modes," in Proc. Of the Eighteenth International Cryogenic Conference (ICEC 18), Mumbai, India 2000, pp. 231-234.

3. Chorowski M., "Combined Thermo-Hydraulic Analysis of a Cryogenic Jet," in Advances in Cryogenic Engineering 45B, edited by Quan-Sheng Shu et al., Plenum, New York, 2000, pp. 1189-1196.

4. J.Pawinski, J.Roszkowski, J.Strzeminski, Mine ventilation (in Polish), Slaskie Wydawnictwo Techniczne, Katowice 1995. 